\title{
Hang with Me-Exploring Fandom, Brandom, and the Experiences and Motivations for Value Co-Creation in a Music Fan Community
}

Research Article

Jessica Edlom ${ }^{1, *}$, Jenny Karlsson²

${ }^{1}$ Geography, Media and Communication, Karlstad University, Sweden

${ }^{2}$ CTF - Service Research Centre, Karlstad Business School, Karlstad University, Sweden

Received August 27, 2020; Accepted October 19, 2020

\begin{abstract}
Active and co-creative audiences are sought, used, tracked and taken for granted in the quest for strong music brands. Fan communities are co-opted to build value for brands and used to foster communication in transmedia marketing campaigns. However, when focusing on audiences and fans' digital media activities, digital traces and numbers, important questions of motivations, expectations, experiences, morals and power structures are often overlooked. Drawing on a digital ethnographic study and an interdisciplinary perspective, we investigate a fan community of the Swedish artist Robyn, both online and offline. The article contributes to the concepts of fandom and brandom and the notion of value. It also adds to the knowledge about the perspective of fans and fans' motivations for taking part and co-creating value in a highly commercialised and strategised music market.
\end{abstract}

Keywords: fandom • brand community • brandom • value co-creation • music industry

(C) De Gruyter Open Sp. z 0.0 .

\section{Introduction}

The music industry is deeply dependent on the affordances provided by social media (Baym, 2012; Choi and Burnes, 2013). Active and co-creative music consumers and fans are sought, used, tracked and taken for granted in the quest for strong music brands (Artieri, 2012; Carpentier, 2011; Duffett, 2013; Jenkins, 2006). Consequently, the music industry must develop sophisticated methods for using fandom as a marketing device (Gamble \& Gilmore, 2013; Gamble et al., 2019), together with spreadable transmedia storytelling (Jenkins et al., 2013; Scolari, 2009; Zeiser, 2015).

User communities for music fans have gradually emerged over time and now manifest as a central user-driven marketing strategy (Gamble et al. 2019). Brand communities (see Muñiz \& O'Guinn, 2001; Schau et al., 2009) can be both brand-generated communities and independent fan-based communities (Bagozzi \& Dholakia, 2002). Guschwan (2012) uses the term 'brandom' to describe a brand-controlled fan community. At the centre of brandom, from a management perspective, is the optimisation of the fan relationship in order to build the brand.

In fan studies, the fan voice and perspective are often prominent (see Chang \& Park, 2019; Click et al., 2013) from a cultural perspective. There is a vast literature on fans, fandom and consumer fandom (see Duffett, 2013; Hills, 2002; Hao, 2020), but there is a lack of knowledge regarding music fans' perspectives and motivations for taking part and co-creating value in a highly commercialised and strategised music market (Baym, 2012) and more specifically in brand communities. There is also often a focus on fans and audiences' digital media activities and

\footnotetext{
* E-mail: jessica.edlom@kau.se
} 
digital traces, but important questions of fans' motivations, expectations, experiences and value co-creation, as well as morals and social power structures, are often left out.

Digital media platform design shapes content and audience actions into data through a process of metrification, enabling commercial organisations to exploit the participation of audiences. Therefore, a better understanding of audiences and fans, giving them a voice, is required in times of data flows and algorithmics (Livingstone, 2019; Schroeder, 2014; Schrøder, 2019; Vesnic-Alujevic et al., 2018). This is also called for by the music industry (see Music Ally, 2019), which recognises the possibilities of collecting big data and insights on consumers to develop a deeper understanding of consumers and thus be able to direct personalised messages to them and control them as both individuals and groups. However, massive data is hard to master and understand, even for the most strategic and professionalised actors, whereas deeper insights in the fan/brand communities are of value for the industry.

Saragih (2019) argues that future research on co-creational experiences in the music industry should focus on how co-creation strategies are used to leverage social focus and how co-creation experiences embedded in music contexts promote social objectives and a better quality of life for consumers. This speaks about the lack of understanding regarding the interpersonal aspect of brand and fan communities; that is, what coming and being together means to the fans. Our study draws on a digital ethnography in order to gain insights into fans and fan communities and their needs and experiences related to a music brand (called for by Duffett, 2013). In the present study, we followed a fan community of the Swedish artist Robyn, both online and offline, to understand the incentives of being a fan and part of a music brand fan community and the connection between the brand and the fans.

Previous research on brand communities, consumer fandom and value co-creation has largely focused on studying what fans do (their practices, behaviours and contributions; see Obiegbu et al., 2019; Sorensen \& Dennan, 2017; Cook \& Everist, 2001) for the sake of the brand. This kind of search for an understanding of fans' motivations and loyalties often lacks the fans' own perspective. There is a danger of speaking for the fans (Duffett, 2013:253), which implies firm-centric processes without involving fans as active participants in the value co-creation process (c.f. Ballantyne et al., 2011; Grönroos \& Voima, 2013; Vargo and Lusch, 2004, 2016). This article argues for the need to speak with fans to understand how value co-creation takes place within fan groups and how this relates to the fans' individual value-creation processes. The full potential of listening to fans and understanding their perspective is yet to be explored in this area.

The aim of this article is, therefore, to develop an understanding of fans and fan communities as part of a music artist brand community. More specifically, fans' value creation and motivation. The article focuses on the following research questions:

1. How do a music brand and fans interact and co-create value within the realm of a music brand fan community?

2. What are the fans' motives and incentives for and experiences of being part of a music brand fan community?

We investigate the aim using conceptual analysis and empirical research. The conceptual analysis focuses on developing our understanding of fandom, brandom and the experiences of music fans, and expanding our knowledge of how fans co-create value by participating in a music brand community. In the present study, we asked fans to be self-reflexive in interviews and a survey. We also created an understanding of the fans and their motivations using a digital ethnography approach, as recommended by Hine (2015) and Pink (2016), in which the fans' actions and ways of co-creating value could be understood through their communication with one another and the artist. This article presents insights into how value co-creation can be realised through online and offline activities and interactions related to fandom and brandom in the context of a music fan community, with fans as main actors.

\section{Theory}

\subsection{Fandom and Fan Communities}

The latter part of the 20th century saw a strong interest in fandom: fans having engaging relationships with popular culture and mediated artefacts (see Holt, 2004) and being part of groups of like-minded consumers with a unifying interest (so-called consumer fandom; see Hao, 2020). Fans were early adopters of the Internet, and their increased access to information and greater speed of social interaction made their activity more public and visible 
(Duffett, 2013b). Fans are highly active in their engagement around the object of their affection (Chung et al., 2018; Fiske, 1992; Gray et al., 2017). However, fans' engagement on social media can be characterised by low to high activity (see Muntinga et al., 2011; Malthouse et al., 2013). Engagement behaviour on social media can also be positively and negatively valenced and categorised according to level of intensity, as outlined by Dolan et al. (2015).

Fans' deep and positive emotional experiences (Baym, 2018; Duffett, 2013) and broad knowledge of their object of interest are often expressed in everyday and social situations as a consistent, loyal and often religious-like allegiance (Löbert, 2012; Obiegbu et al., 2019). At the centre of fandom is the ability to transform personal feelings into social interactions (Jenkins, 2006). Fan communities form around a common interest and offer a sense of belonging to fans (Duffett, 2013b). Duffett (2013) claims that fandom should be studied not just by looking at the individual fan, but at how fans find intimacy and build relationships with those around them, developing a kind of family. In a study about the music artist Lady Gaga, fans even went as far as to describe the artist as taking on a kind of parental role in the fans' lives (Click et al., 2013:361). Fans felt part of a family called 'Little Monsters', associating Lady Gaga with the name 'Mother Monster'.

The fan phenomena of today are moving faster than ever before and can take place anywhere and anytime. Online interaction has changed fan communities into 'a non-stop process of social effervescence' (Hills, 2003:181), rather than being networks of local culture. These communities have become a portable haven where fans can belong (Sandvoss, 2005). Maffesoli's (1996) concept of tribe elaborates on the fan community by describing an affinity-based group with a common affective repertoire and 'collective privacy' (1996:91). The affective belonging is reinforced by technology both within and across groups. Adams and Smith (2008) drew on Maffesoli's concept to describe electronic tribes as fluid, postmodern groups that want to belong together, interact socially and share information within the tribe, actions that are facilitated by social media and its affordances. Studying the fan army of the South Korean boy band BTS, Chang and Park (2019) drew on the tribe concept to explain emerging global music fandom - how private fandom, its tastes and its desires have transformed into 'cultural, political, and economic expression in the public realm' (2019:260)—via digital intimacy and transnational locality, made possible by social media. These kinds of tribes organise themselves online without any kind of organisational structure. This is central to becoming an influential and often global fan group made of members who share and create values and distribute content as they see fit.

\subsection{Brand Communities and Value-Creation Processes}

One aspect of fan community activity is the action that the fandom object (the product or brand) benefits from commercially. The management of a brand recognises the possibilities of using fans in branding and transmedia marketing and seeks to optimise the relationship between the brand and fans. This kind of fan community can be created by the brand itself: a brand community (see McAlexander et al., 2002; Muñiz \& O'Guinn, 2001; Schau et al., 2009). Several definitions of brand communities have been suggested. Muñiz and O'Guinn (2001:412) define brand community as 'a specialized, non-geographically bound community, based on a structured set of social relationships among admirers of a brand', whereas Cova et al. (2015:466) define it as a 'co-consuming group of people with a common interest in a specific brand that creates a parallel social universe (subculture) with its own myths, values, rituals, vocabulary and hierarchy'.

The organisational activities of steering, measuring and monetising fan communities in order to build brands are profoundly enabled by social media (see, for example, Guo, 2020). Guschwan developed the term 'brandom' to describe fan culture 'engineered by brand managers eager to cultivate consumer labour and loyalty while preempting the possibility of resistance that participatory fan culture promises' (2012:26). The term brandom has partly been elaborated in relation to sports (Guschwan, 2012) and film industry (Marsh, 2014) but not regarding the music industry. O'Reilly, Larsen and Kubacki (2013) explore music brands and fandom from a consumption perspective. To further elaborate on the term in cultural industry, but more specifically to build on the distinction between brandom and fandom, we find it important to understand the fan perspective of taking part in this and to create and understanding of the sociological dimension of emotions of fandom and brandom (Yeritsian, 2018).

Some argue that a 'new economy of fandom' (Galuszka, 2015, building on Fiske, 1992) has emerged due to new conditions for online fan brand communities, empowering and giving fans new roles as stakeholders, sponsors, investors, filters and co-creators of value. Thus, (fan) consumers play a pivotal and dynamic role in value co-creation within the realm of brand communities (Ind et al., 2013; Schau et al., 2009) by acting as 'providers and beneficiaries, thereby co-creating value for themselves, for brand communities, and for organisations' (Pongsakornrungsilp \& Schroeder, 2011:320), including content, products and services (Muñiz \& Schau, 2011). 
Brand communities can offer brand loyalists a place to assemble, often of their own accord, to discuss and share their passion for particular brands (Muñiz \& O'Guinn, 2001). Nevertheless, research has shown that brand communities lead to many beneficial outcomes for brands, including stronger loyalty and purchase intentions (Algesheimer et al., 2010). Co-creative fan practices in contemporary brand communities serve brands and the media industry at large (Artiera, 2012; Arvidsson, 2005; Carpentier, 2012; van Dijck, 2014; Zwick et al., 2008). Fans, in this sense, can be seen as working for the industry as free labour, a concept that has been increasingly used since Terranova's (2000) analysis of user productivity in the networked digital economy and the ways in which such productivity might be exploited by capital. The use of fans as free labour-also referred to as emotional labour (Hochschild, 2012) or relational labour (Baym, 2018) —offers the industry a way to lower the costs of production, marketing and consumer relations and 'spread its risky business across a broad spectrum of stakeholders' (Fast et al., 2016:974). The fans seem to accept this, presumably finding the work they do to be rewarding and of value to them.

Traditionally, value has been understood as something that is realised when money is exchanged for products and services, which implies that value is produced by firms and consumed by customers. (Grönroos, 2011; Vargo \& Lusch, 2004, 2008). However, in the last decade, traditional demarcations between producers, such as music actors and consumers (i.e., fans and audiences), have been blurred and changed. Value can rather be seen as co-created in collaboration with customers as they subjectively experience, perceive and determine value when using products and services.

To create prerequisites for customer value creation, an organisation and its customers (and other actors in the service ecosystem) contribute and integrate resources, such as information, knowledge and skills (Vargo \& Lusch, 2008, 2016). Grönroos and Voima (2013) distinguish three spheres where resources are integrated and value may be created: the provider (organisation) sphere, the joint sphere and the customer sphere. In the provider sphere, the organisation acts as a value facilitator with a focus on integrating resources to facilitate customers' value creation, for example, by sharing information about a new album, concerts, tickets or merchandise.

In the joint sphere, the organisation and customers act as co-creators of value as they integrate resources through direct interaction. This is considered a dialogical process between the provider (artist) and the customer (fans). An example is creating a game that fans can play to win tickets to a concert.

In the customer sphere, value is created by customers themselves in use, outside direct interaction with the organisation/provider (Grönroos \& Voima, 2013), such as the fans listening to a new album with friends at home. However, different customers may perceive the same product or service differently depending on the occasion and social context (Edvardsson et al., 2011). Thus, it can be suggested that the listener may perceive the new music (or another type of service provided by the artist) differently if they experience it by themselves or together as a community.

Through the use of social media, the organisation has an opportunity to follow actions and interactions between customers as well as to co-create value with customers to a larger extent. Social media has also shifted the boundaries of marketing and consumer behaviour (Gamble \& Gilmore, 2013). While moving away from the traditional view of marketing and value creation, consumers have also been given increasingly active roles in the marketing process (Bloom, 2006). Gamble and Gilmore (2013) argue that this change is partly perceived by firms as a loss of control, but still a necessity.

In sum, we study how fans in a music brand community interact and co-create value and explore their motivations for participating and being active in this relationship. This study addresses the need to understand individual and social aspects of fandom and how it can be connected to a brand.

\section{Method}

To create an understanding of how fans, fan communities and a music brand interact and co-create value, we employed an ethnographic approach. This approach allowed us to gain insights into the relations, actions and social lives of fans related the object of interest, create a holistic understanding of the actual context and community (O'Reilly, 2012:1) and observe and follow the flow of conversation and the circulation of the fan engagement around the object of fandom (Hine, 2015). More specifically, a digital ethnography (Hine, 2015) was used, a method that enables to focus on the social spaces that emerge through the use of the Internet and beyond it.

Today, the Internet is embedded in people's everyday lives and is part of an individual's experiences. In line with boyd's (2015:4) argument that it is important to acknowledge 'continuities between online and offline contexts', we followed the activities of a fan group both online and offline, which allowed us to gain insights into the experiences of 
fans. Traditionally, ethnography focuses on a geographic place or space, but with a digital, networked study object, the focus should be on mobility in relation to what is happening during the study and across platforms, becoming a multi-sited ethnography (Marcus, 1995). We thus followed 'the thing' in order to understand it, as suggested by Marcus (1995).

\subsection{Case Background and Research Objective}

A fan community related to the Swedish music artist Robyn was selected as a case for this study. The case was selected for three reasons: first, Robyn is a well-known Scandinavian artist with a large fan base. Second, Robyn made a comeback in late 2018 and created a new Facebook fan community that quickly grew to include fans from all over the world. Third, this case provides a rich empirical context because the artist uses social media liberally to communicate with her fans as well as the fans who are active in their relationships both with the artist and among themselves, as recommended by Hine (2015). Robyn is active on Instagram, Twitter, Facebook and YouTube, which all are used for marketing and communication with the fans, in general.

The Facebook group 'Konichiwa Bitches' (KB) is rather a new fan group, started by Robyn and her management team in 2018 as part of a release campaign for her new album 'Honey'. One example of the marketing events is Robyn's collaboration with Red Bull in the form of a gamified app that allowed fans to compete for tickets to a concert of Robyn as part of the 'Red Bull Secret Gig' the same year in Stockholm, Sweden. Activity in the KB community originally related to this event but continued when Robyn went on tour in Europe, Canada and the US. Soon, the KB group grew to encompass engaged fans around the world-over 3,200 to date. Initially, the group content primarily consisted of branded content and information about campaign events but evolved into more regular fan conversations over time and is now mainly built on fan interactions.

\subsection{Data Collection}

Conducting a digital ethnography is a matter of engaging with the field, watching what happens and listening to what is said (Hine, 2015; O'Reilly, 2012; Pink, 2006), which can be challenging due to the massive amount of data, as well as the heterogeneousness and complexity of the Internet, as it is in constant change and movement (Hine, 2015). We followed the argument of Hine (2015) and Markus (1995) using a multi-sited ethnography approach, both online and in real life (IRL), with several data collection techniques.

Data collection took place between fall 2018 and summer 2020. First, we searched for information about the artist in general and about her fans in particular on social channels and digital news media. We followed fan conversations and participated in blogs and social media platforms (as described by Hine, 2015; Pink, 2006; Postill \& Pink, 2012). The mapping resulted in an overview of the fan community and identified where most fan activities took place (e.g., the KB group on Facebook, which we gained access to).

Second, we conducted a small qualitative survey in the KB Facebook group. The survey was conducted as a pilot study in order to identify why fans are active members in the group and how they interact. In total, eighteen fans answered the survey.

Third, we invited fans to an interview, and then conducted semi-structured interviews with four fans in the KB group to deepen our knowledge and gain a broader understanding of the fans, their perceived value of being a member of the fan community, their feelings and experiences, and the marketing efforts by the management team. Probing questions were used to gather more detailed descriptions, which helped prevent misunderstandings in the respondents' replies. In conjunction with a concert, five more respondents were interviewed. We also identified and interviewed three fans (USA) in the KB group who stood out as superfans as they arranged events playing Robyn music. These superfans had been some of the most active group members and exclusively invited by the management team to be administrators of the Facebook group. To understand the brand perspective, we also interviewed four members of Robyn's management group. In total, sixteen interviews were conducted with both men and women from four countries: the UK, Canada, the US and Sweden. Interviews lasted between 30 and 65 min (except for one that was only $14 \mathrm{~min}$ ) and were audio recorded and transcribed. Contracts were signed to assure the respondents' anonymity throughout the process of collecting, analysing and presenting the data.

Fourth, we participated in concerts and dance parties, interacting with other fans and experiencing the event ourselves. In 2020, several virtual dance parties were organised by Robyn and a group of superfans as live streams, which enabled us to observe the fans' participation and the online discussions related to the live streams. As a part 
of the digital ethnography, we also actively participated in the KB group, conducting participant observations online, writing comments and posts, liking other posts, talking to fans and so forth. We have also actively collected data by taking screenshots of posts and conversations during the whole period of data collection.

\subsection{Data Analysis}

To identify deep and rich descriptions of the context in which the phenomena occur-that is, the fandom and brandom - we followed an inductive approach inspired by grounded theory (Glaser \& Strauss, 1967; Strauss \& Corbin, 1998) for our data analysis. As we sought to understand the motivations, experiences and value creation of fans within these contexts, we adopted the Gioia methodology (2013), which enables scientific theorising about people's experiences. This methodology gives the respondents a strong voice in guiding the data analysis, arguing that respondents are able to explain their thoughts, intentions and actions.

As recommended by Gioia et al. (2013), we started the data analysis by coding the extensive data set by identifying empirical codes and constructed empirical phrases closely related to the respondents' own descriptions (the first-order concepts that can be found in Table 1). We then constructed second-order themes by combining empirical explorations with theoretical reflections about fandom, brandom and value creation. In the aggregate dimension, the key themes were abstracted further into common headings. Table 1 illustrates the three types of 'individual fan motivations', three types of 'collective fan motivation' and two themes related to 'brand motivations' identified through our data analysis.

These themes and aggregate dimensions are explored and elaborated on in the section 'Findings'. The empirical exploration outlines a framework for creating an understanding of fans and fan communities as part of a music brand universe that is further reflected upon in the section 'Discussion, Contributions and Future Research'.

\begin{tabular}{|c|c|c|}
\hline $1^{\text {st }}$ Order concepts & $2^{\text {nd }}$ Order themes & $\begin{array}{l}\text { Aggregate } \\
\text { dimensions }\end{array}$ \\
\hline $\begin{array}{l}\text { - Experiencing music and artist; enjoying, feeling passionate about, loving } \\
\text { - Experiencing self-value; pride, reward } \\
\text { - Sense of belonging/togetherness; feeling of intimacy, belonging, part of something }\end{array}$ & $\begin{array}{l}\text { Individual emotions/fan } \\
\text { feelings }\end{array}$ & \multirow{3}{*}{$\begin{array}{l}\text { Individual fan } \\
\text { motivations }\end{array}$} \\
\hline $\begin{array}{l}\text { - Identifying with artist values; independent, innovative, creative, equal, honest, unique } \\
\text { - Identifying with group; free, open, collaborative, diverse, creative } \\
\text { - Expressing one-self/the identity; persona on social media } \\
\text { - Finding/expressing role in the group; level of activity/engagement, closeness to the centre, } \\
\text { fan-superfan-executive }\end{array}$ & Self-identity/being a fan & \\
\hline $\begin{array}{l}\text { - Expressing/showing one-self; both online and offline } \\
\text { - Sharing/spreading information/content (active)/following group activities (passive) } \\
\text { - Sharing/helping others, connecting } \\
\text { - Create/initiate activity and interaction (online and offline) }\end{array}$ & Individual activity & \\
\hline $\begin{array}{l}\text { - Sharing experiences } \\
\text { - Being together; intimacy, part of something, friendship, inclusiveness, inviting, generous } \\
\text { - Welding/motivational emotions; feelings of being part of something, joyful, open, positive, } \\
\text { cool, unpretentious belonging }\end{array}$ & $\begin{array}{l}\text { Shared emotion/collective } \\
\text { feelings }\end{array}$ & \multirow{3}{*}{$\begin{array}{l}\text { Collective fan } \\
\text { motivations }\end{array}$} \\
\hline $\begin{array}{l}\text { - Sharing common interest } \\
\text { - Family feelings and values; belonging together, watch each other grow, warm, positive, } \\
\text { inclusive community }\end{array}$ & $\begin{array}{l}\text { Group-identity/being part of } \\
\text { fandom }\end{array}$ & \\
\hline $\begin{array}{l}\text { - Sharing/helping each other; getting access, information/news, connecting, travelling } \\
\text { together, offering accommodation } \\
\text { - Co-creating, collaborating; e.g. fan dance parties, meetups, playlists } \\
\text { - Relationship/group building; bring people together }\end{array}$ & Common/collective activity & \\
\hline $\begin{array}{l}\text { - Start communication, initiate, facilitate } \\
\text { - Create activities; app competition for secret party, playlists, online DJ parties } \\
\text { - Connecting to/with executive fans }\end{array}$ & Facilitating activity & \\
\hline $\begin{array}{l}\text { - Create branded content; record release, competitions e.g. for tickets, meme competitions } \\
\text { - Create activities; app competition for secret party, playlists, online DJ parties } \\
\text { - Sharing news, exclusive access }\end{array}$ & Brand building & $\begin{array}{l}\text { Brand } \\
\text { Motivations }\end{array}$ \\
\hline
\end{tabular}

Table 1. Data structure 


\section{Findings}

This section describes fans' engagement with a music artist and a fan community regarding individual, collective and brand-related motives and their sense of what brings value. As the individual and the collective perspectives of the fan motivations are closely related, results of these themes are presented in the same section: 'Individual and Collective Fan Motivations', starting with the emotions/feelings, followed by identity and activity (2nd order themes in Table 1). Brand motivations are presented in the final section of the findings: 'Brand Motivations and Brand-Value Perspective'.

\subsection{Individual and Collective Fan Motivations}

\subsubsection{Indestructible - individual emotions and self-identity of being a fan}

At the centre of being a fan is the experience of the fan object and the feelings connected to it. Being a Robyn fan allows individuals to experience positive and affirmative feelings such as joy, love and pride. One respondent, Eric, expressed his emotions: 'It is about how Robyn makes you feel. It relates to her music —upbeat, honest, and emotional in a very positive way'. The data suggests that fans engage and identify with the artist Robyn based on the perceived values related to her. Being (or being perceived as) genuine, honest and having a strong ideology are proven factors that help shape brand equity (Aaker, 1997; Gilmore \& Pine, 2007; Morhart et al, 2015). Authentic brands are associated with a high level of credibility and integrity. This is also something that lays the foundation for fans to engage with Robyn. She is perceived as authentic, unique and down-to-earth. Anna, described, 'Robyn is putting effort into being sincere with the fans. We [expect] her to act as herself'. As Robyn has (and controls) her own music label, the fans also suggest that Robyn stands for independence and freedom, like the right to being oneself, bringing together the gay and queer community and advocating for human rights.

Robyn is also seen as an icon, an influencer and a creative and innovative entrepreneur, both regarding her music and relationship with her fans and other brands. However, collaborations with other brands have, to some extent, been perceived by fans as abandoning her ideology. For example, some argued that Robyn's collaboration with Red Bull did not align with her brand: 'I'm slightly negative. But I guess it is really hard for an independent artist to make money and get enough exposure' (Kim). Thus, even though the respondents expressed hesitation regarding marketing efforts that seemed too commercial, they still accepted them and even added to the marketing campaign by spreading it in the group's channels.

Central to fandom is the will to display and share one's affection with the object of fandom (offline and online), in other words, to express oneself as a fan. This can include buying and wearing artist merchandise, mimicking the artist's style in hair, clothes and music, and documenting it on social media. Fans' individual expressions and fan engagement are also based on values related to other fans; social aspects, like shared emotions, experiences, information and practices, are central to fandom (Jenkins, 1992, 2006; Duffet, 2013).

Data shows that sharing and supporting other fans are central values in the Robyn fan community. Today, the KB group is mainly managed by fans and is a group for fans to share information, news, and experiences and talk about Robyn. Interactions in the group are participatory and active. There is a substantial amount of action, such as sharing news about music releases, concerts, artistic processes, other fan-related content or experiences and feelings connected to the artist and her music.

\subsubsection{Show me love-collective emotions and group-identity}

The fan group provides opportunities to meet other fans. One respondent, Bill, described this as something you want to be a part of: 'It seems like a positive community, which is unique for Robyn—a collective thing. [The group] is bringing people together'. The togetherness, a collective intimacy, and 'being part of' something that is open and inviting, but also 'joyful', 'positive', 'unpretentious' and 'cool', are the central motivational values for members. These values are also representations of the artists and are central to the shared fandom and bonding of the group. Another respondent described the joy of becoming a member of and active fan in the group by participating as a gamer for the Red Bull Secret Gig: 'The interaction with other fans was surprisingly positive... They were so open, generous, patient'.

Being a member of the KB group allows fans to engage with Robyn and co-create value with her. Group interactions allow fans to experience closeness with both other fans and the artist, regardless of their geographic location. One respondent, James, stated, 'The Konichiwa Bitches group is special. It makes you feel like you are 
more in touch with [Robyn]'. The close connection to the artist makes the relationship almost like a friendship: 'The feeling of being more like a friend makes you feel like you are part of the inner circle, not that it's just general marketing to anyone' (Anna).

Meeting new people and making new friends from all over the world with the same interest is a great benefit for the members of KB. Some fans have even started to arrange Robyn dance parties to facilitate fan meetings and share the music interest. The data shows that being a member of a fan community online creates a feeling of belonging. You have to be accepted to become a member in the closed group, and after that, you are inside the 'family' (Click et al., 2013) or the 'tribe' (Maffesoli, 1996), creating fan intimacy and transnational locality (Chang \& Park, 2019). As Julio explained, 'I think it's really cool to be part of something bigger than ourselves and see how Robyn has impacted everyone's life differently... It's cool to watch each other grow'.

Negative posts and comments are almost non-existent, but when such a post occurs, it is instantly managed by the administrators, who remind the poster about the unwritten rules and positive spirit of KB in order to avoid negative interactions and experiences. The 'friendly', 'supporting', 'inclusive' and inviting aspects of the group were emphasised in the study by several respondents and are often central in KB interactions. Both examples are exemplified in Figure 1.

The relationships built on social media create prerequisites for people to meet IRL, for example, when travelling to concerts, sharing accommodations, or taking part in fan events. As Bill explained, 'KB brings people together... I met one guy IRL at a concert, he came from the US to the concert in Canada'. With social media, it is easy to connect with other people who share the same interests, regardless of where they are physically. Fan meetups can be organised by the management team or by members themselves, in the KB group or in other forums. For example when the KB group was started, Red Bull also created another Facebook group called the Red Bull Secret Gig Game, which was connected to an app game with the same name. This also drew fans together both online and offline. As Julio said, 'When playing, I got to know [Robyn's] fans, who turned out to be really nice people. It was nice to meet them again online and share experiences of playing and the show'. Fans also created messenger groups and private Facebook groups, inviting others to fan meetups to help each other in the game.

The fans that come together at concerts feel a strong connection after meeting and creating common experiences. This feeling was described by Anna: 'Those who were at the concert had made an effort and there was a "fellowship" in that we were knitted together. I recognised several who were there, feeling that we belong together somehow'. The KB group also allows fans who are unable to attend a live concert to get insights about the concert and to experience it in some virtual way.

The data shows a connection between online and offline in the fan community. The group is spread all over the world (although with a European and North American dominance), giving fans the opportunity to meet others like them without needing physical proximity: 'I feel like a part of something. I feel less alone and less weird, when I know that others are obsessed as well' (Kim). During the Covid-19 pandemic in the spring and summer of 2020, online dance parties and DJ sets were held by superfans from 'The Robyn Party/This party is killing you' and by
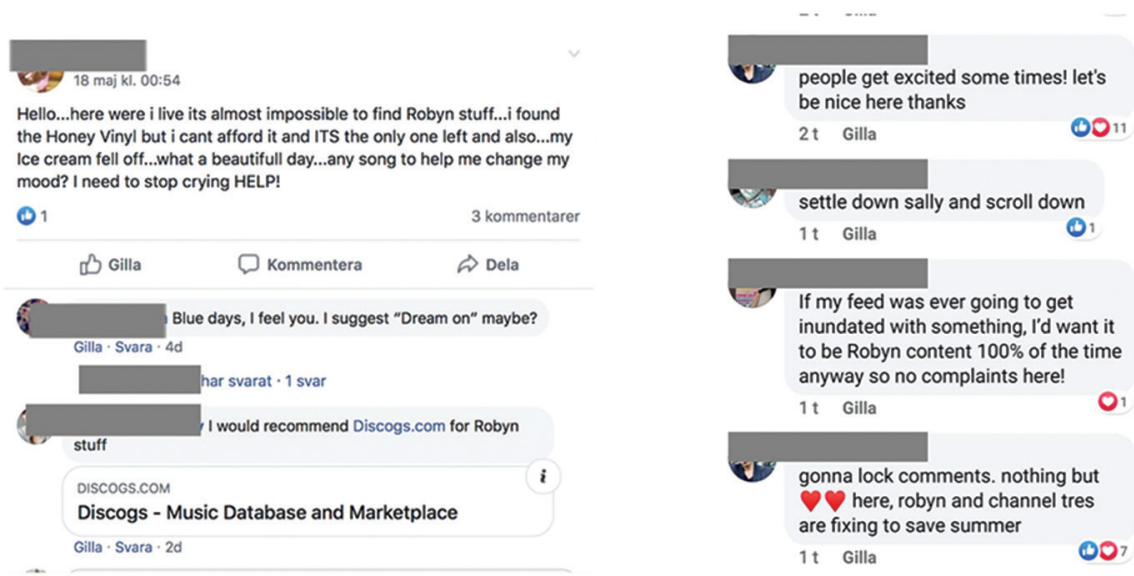

Figure 1. Helping, recommending and supporting in KB. KB: Konichiwa Bitches. 


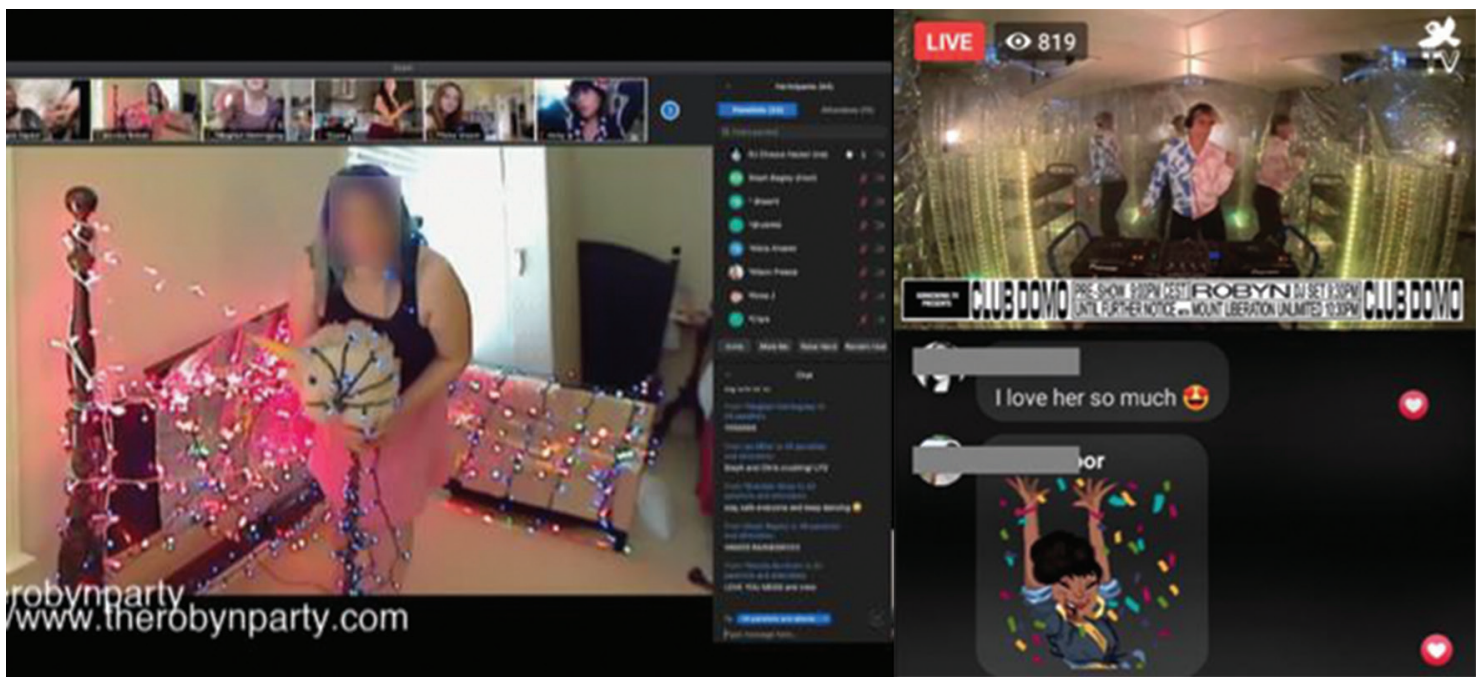

Figure 2. Online dance parties, by fans and Robyn herself.

Robyn herself, inviting people to dance in their homes and chat with each other on the streaming platform, connecting the online and the offline, as seen in Figure 2.

\subsubsection{We dance to the beat-individual and collective fan activity}

From an individual perspective, the fan activities in the community serve several purposes: to portray oneself as a fan within the group, to build an identity and become someone in the group, to connect and communicate, to share and spread feelings and information and to initiate interaction. These activities can take different forms: sharing (e.g., experiences or information/news about and access to concerts and music releases), connecting and helping one another (e.g., travelling together, offering accommodation), and co-creating and collaborating (e.g., organising fan dance parties and meetups, and creating common playlists). Bringing people together and building relationships is a central value of the individual fan and the community.

The communication and connections within the community and Facebook group show that the fans differ in their degree of social media engagement (Muntinga et al., 2011; Malthouse et al., 2013), mostly positively valenced (Dolan et al., 2015). The activity varies between fans who are more or less active and engaged and fans who are more or less close to the management team (the so-called superfans). However, as our findings show, fans can be passive followers and participants in the group but still be intense in their fandom. Passive followers are not active in posting and sharing information and fan expressions on social media, but rather experience what other fans and the artist post and share. As one participant, Anna, explained, 'I am a follower of the group, and not so active in posting myself. I am not very active on social media in general, but I want to be able to take part [in, for example, Robyn's] music and interviews'. It is about being part of and following a community and a fan object on one's own terms, whether or not one is an active community participant.

Active fans share information, content and experiences, invite others to activities, post questions and connect with others in the community. The incentive for fans to share news and (sometimes exclusive) content about the artist with their friends is mainly just to share their interests with their friends, even if they understand that it adds to a commercial campaign: 'It is important to share about anything you feel passionate about, and I am passionate about Robyn's music' (Bill).

Most of the respondents described themselves as very engaged fans or superfans. However, a few people in the KB group are more active than others. They are seen as more influential by others in the group. As one participant, Bill, explained, 'When I post in the group, I write something to talk about, to get people to interact about. I want to try to get people to bond'. The top fan badge on Facebook (introduced on Facebook in 2018) is something that resonates with some respondents in the study. It identifies the most active users on a page, i.e., how active you are as a fan. It becomes a kind of reward and is an indicator of value to oneself and to others in the fan group. 
Some superfans also arrange activities-such as competitions, challenges, parties (both online and IRL) and meetups-that has been highly recognised and appreciated by other fans. A few of these superfans are also administrators of KB (invited and assigned administrative roles in the Facebook group by the brand management team). These fans also help manage certain events, giving fans direct access to appearances by the artist and artist materials. Research on fan creation has previously partly focused on innovation and contributions on the creative music work and the funding of it (e.g., on the music artist Imogen Heap, see Cook \& Everist, 2001, or HepworthSawyer et al., 2019). In the case of our study, the fan activity is primarily focused on other types of values, such as relations and experiences.

\subsection{Brand Motivations and Brand-Value Perspective}

\subsubsection{Keep this fire burning-facilitating activity}

The KB group was started by Robyn's management team as part of a marketing campaign for her record 'Honey', in association with the Red Bull Secret Gig competition in fall 2018. Initially KB functioned as a typical brand community (e.g., Muñiz \& O'Guinn, 2001) with the aim of serving the brand and its fans via consumer/fan participation and creativity. The management activities in the group (such as posting about the record and the competition) were frequent, aiming to facilitate fan activity and community, initiate conversation, and stir engagement around activities and the artist. The goal was to allow fans in the group to interact and to make and spread content, both inside and outside the group, which was of great value for the brand.

Today, there are fewer posts by the management team, but these posts are perceived by the fans as positive as they are a way of getting first-hand and 'inside information' about and exclusive access to the artist. Robyn herself posts in the group from time to time, which makes group members feel close to her and her being 'authentic'. Still, the core purpose of the community for Robyn's management team is to build the brand via branded content connected to, for example, music releases, concerts, online DJ parties and collaborations with other music actors.

\subsubsection{Be mine-brand building}

The group functions as a hotbed for Robyn's fan community as a whole, which spreads content outside the community, helping to market the brand. The management team appreciates how the fan group, and more specifically the superfans, helps to market Robyn: 'We are so lucky to have them. They are doing it so well. Like on top of everything' (Tina, management group). The fan group is seen as a collective driver of communication, even coming up with ideas and information that the management team can use.

Some fans point to the fact that they are asked to take part in and spread marketing and branding content both inside and outside the group but express that this is okay as it gives them something in return. They also express that marketing is not the sole reason of the group. James argued, '[Robyn] didn't just create the group for marketing strategy reasons, I'm sure. She wanted there to be a group'. Reflecting on the aim of using the KB group for the marketing campaign in relation to other values, Ulrika argued, 'It's okay to get fans to do things for you [as an artist] as long as it's nothing unpleasant. It's ideal for meeting people and having a good time'.

Participating in creating and offering interesting content within the fan group, and thereby facilitating the fandom, is central to a brand community from the brand perspective. Building long-term relationships with the fans in the community is also important. As some fans are more active and influential within the group, they are able to make more brand-oriented content resonate within the group. It is especially important for the management group to build relationships with these superfans to sustain relationships in the community that are not foremost interpreted as branded content or content with a marketing purpose.

\section{Discussion, Contributions and Future Research}

This article continues to develop an understanding of the concept brandom (initiated by Guschwan, 2012), as well as the connection between brandom and fandom in the music industry. More specifically, the article explores how value-creation processes take place in the context of a music brand community with the music artist, management 


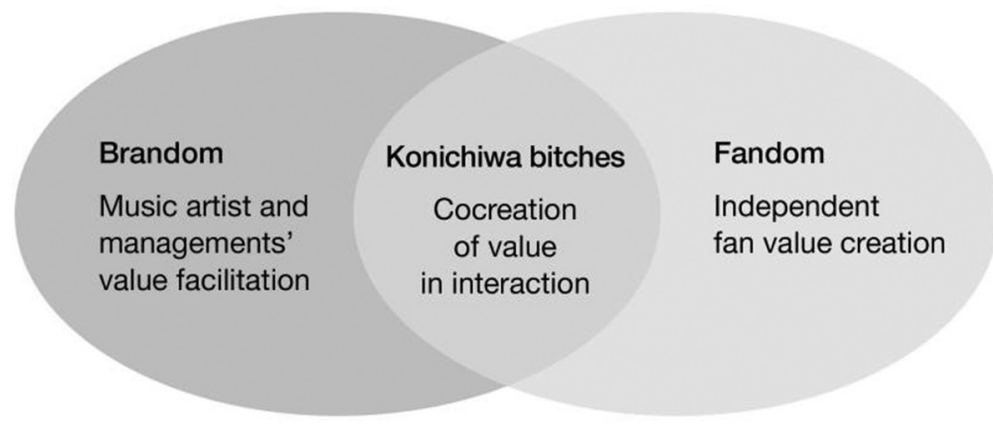

Figure 3. Distinction between brandom, fandom and joint sphere. Inspired by Grönroos and Voima's model of value-creation spheres (2013:141).

team and fans as main actors. Figure 3 illustrates a model that distinguishes the brandom and the fandom spheres according to their respective characters and common features. Even though the spheres are separated, they are interrelated and interconnected.

The three value-creation processes, illustrated by Grönroos and Voima (2013) as spheres, are central to understanding fan communities as part of a music brand universe. The music provider's value facilitation relates to brandom and the way music actors produce resources (such as information, knowledge and skills) and the process of facilitating fans' value creation. The aspects of the artist's brand that generate potential value in use can include products and services, such as games to win concert tickets; information about tickets, concerts and albums; DJ sets; TikTok challenges; and playlists for streamed music. The artist's management team and record label are in charge of these processes, which can take place physically and virtually.

The joint sphere in the model represents value co-creation in the interaction between the provider (brand/artist/ management) and the user (the fan). In the joint sphere, both integrate resources to co-create value, such as when they directly interact on social media through a game played in an app or a Robyn party. In our study, the KB group became an arena for interactions between the management team and the fans, which generated value for both the brand and the fans.

Value creation also occurs in the customer sphere-the fan group - that has nothing to do with the artist as a brand; rather, it involves the experience of being a fan and coming together. This sphere relates to fandom, how fans interact with one another independent of the music artist, both on social media and in person. Independent value creation can involve fans sharing information and playlists with each other, creating parties, and offering help and accommodation. Independent social value creation represents social aspects as shared values, with fans supporting one another and ultimately building community, which creates and supports a feeling of belonging.

From a brand perspective, our findings suggest that in addition to utilising the fans' activities in marketing and branding through the use of social media and an online brand community (e.g., creating VIP experiences), the provider can learn from the fans and gain insight into fan interactions and experiences also without interacting directly with the fans. Based on the access to the fandom and the understanding of fans and their value (co-) creation processes, we suggest that artists/managements are able to create business strategies for positive fan experiences. A provider can integrate information and knowledge within an organisation's processes to develop existing and new services to facilitate fans' future value-creation processes. The brand community plays a dynamic role in the value co-creation process both as providers and as beneficiaries (as proposed by Pongsakornrungsilp \& Schroeder, 2011). At the same time, the brand community serves the brand with fan work (emotional/relational labour) performed by the group, creating content and events, spreading information and so forth.

From a fan perspective, this article contributes to an understanding of the values and motivations fans base their relationships and fandom on. This involves both the artist and the values that fans develop together with other fans. Although initiated by a brand management group, our findings suggest that the KB Facebook group is not only a brand community, nor is it only about brandom. Within the fan sphere, the fandom creates value for the fan both on an individual and on a collective scale. More specifically, members of KB argue that the group gives them 
a feeling of belonging and togetherness while also providing access to information and the network. Robyn and her management team, as service providers, facilitated value creation for the fans by starting the KB group and providing fans with priority access to news, concerts, happenings and more. Fans experience this as a way of getting first-hand and 'inside information'. What started as a value facilitation process by Robyn and her management team, with the purpose of encouraging communication around the brand and cultivating fan engagement and value cocreation, has transformed into an active fan community with its own agency.

Overall, the interaction in the fan group suggests that it acts as a fan community or a tribe or a family, creating connections and intimacy and allowing members to participate actively and share both digitally and IRL on a local and global scale. The fan group functions and organises itself as an electronic tribe without an active organisation (Chang \& Park, 2019). Our results did not show any major tensions within the group; none of the respondents expressed hierarchies as problematic. The superfans were instead seen as facilitators by the other fans. Nevertheless, how fan hierarchies are built and manifested in fan communities and if these hierarchies affect value co-creation within the community are areas for future study. Furthermore the close connection between the fans and the artist could be elaborated on in future research, more specifically, to create an understanding of possible parasocial interaction (Horton and Wohl, 1956) relationships between artists and fans. This possible illusion of familiarity and relationship is amplified in promotional culture of today.

Our findings reveal a partial migration from brandom to fandom in the brand community, going from a brandcontrolled fan community to a more independent one (Bagozzi \& Dholakia, 2002; Guschwan, 2012). This is possible due to strong fandom and the artist's close connection to her fans (even before the Facebook group). Additionally, the brand allows the group to create and co-create content in an open and uncontrolled way, which is part of a management strategy. The strong fandom in the brand community also seems to be due to some influential individuals in the group who have taken on an active and inclusive role as superfans. As these individuals also cooperate with the management team and are even given executive and administrative roles within the group, joint value creation is strengthened, which benefits both the artist brand and its marketing endeavours and the fan community. This also reflects the new suggested fan roles (Galuszka, 2015), primarily as value co-creators, stakeholders and filters. Since this article is exploring one specific music artist and fan universe-one where the fandom is strong-we propose that our contributions also can be elaborated on in other contexts and conditions.

By responding to the aim and research questions, this article contributes to an understanding of how a brand can develop prerequisites for future value creation using insight from the fans themselves regarding what creates value for them. It can be counterproductive to utilise only a marketing perspective in relationship building within a brand community or fail to participate in fan activity or listening to the fans. The relationship flows both ways. Overall, this study has contributed to the call for a better understanding of fans and fan communities and gives them a voice in a time when both the research and the media industry are focusing more and more on the data traces that audiences and fans leave.

\section{References}

Aaker, J. L. (1997). Dimensions of brand personality. Journal of Marketing Research, 34(3), 347-356.

Adams, T. L. \& Smith, S. A., eds. (2009). Electronic Tribes: The Virtual Worlds of Geeks, Gamers, Shamans, and Scammers. University of Texas Press.

Algesheimer, R., Dholakia, U. M., \& Herrmann, A. (2005). The Social Influence of Brand Community: Evidence from European Car Clubs. Journal of Marketing, 69(3), 19-34.

Arvidsson, A. (2005). Brands: A Critical Perspective. Journal of Consumer Culture, 5(2), 235-258.

Artieri, G. B. (2012). Productive Publics and Transmedia Participation. Participations: International Journal of Audience Research, 9(2), 448-68.

Bagozzi, R. \& Dholakia, U. (2002). Intentional Social Action in Virtual Communities. Journal of Interactive Marketing, 16(2), 2-21.

Ballantyne, D., Frow, P., Varey, R. J., \& Payne, A. (2011). Value Propositions as Communication Practice: Taking a Wider View. Industrial Marketing Management, 40(2), 202-210.

Baym, N. (2012). Fans or Friends? Seeing Social Media Audiences as Musicians Do. Participations, 9(2), 286-316. Baym, N. K. (2018). Playing to the Crowd: Musicians, Audiences, and the Intimate Work of Connection. New York: New York University Press. 
Boyd, D. (2015). Making Sense of Teen Life: Strategies for Capturing Ethnographic Data in a Networked Era. In: E. Hargittai and C. Sandvig, eds., Digital Research Confidential: The Secrets of Studying Behaviour Online. Cambridge: MIT Press.

Carpentier, N. (2011). Media and Participation: A Site of Ideological-Democratic Struggle. Bristol: Intellect.

Carpentier, N. (2012). The Concept of Participation, If They Have Access and Interact, Do They Really Participate? Communication Management Quarterly, 21, 13-36.

Carpentier, N. (2016). Beyond the Ladder of Participation: An Analytical Toolkit for the Critical Analysis of Participatory Media Processes. Javnost-The Public Journal of the European Institute for Communication and Culture, 23(1), 70-88.

Chang, W. \& Park, S. E. (2019). The Fandom of Hallyu, a Tribe in the Digital Network Era: The Case of ARMY of BTS. Kritika Kultura, 260-287

Choi, H. \& Burnes, B. (2013). The Internet and Value Co-Creation: The Case of the Popular Music Industry. Prometheus, 31(1), 35-53.

Chung, E., Farrelly, F., Beverland, M. B., \& Karpen, I. O. (2018). Loyalty or Liability: Resolving the Consumer Fanaticism Paradox. Marketing Theory, 18(1), 3-30.

Click, M. A., Lee, H., \& Holladay, H. W. (2013). Making Monsters: Lady Gaga, Fan Identification, and Social Media. Popular Music and Society, 36(3), 360-379.

Cook, N., \& Everist, M. (Eds.). (2001). Rethinking music (p. x). Oxford: Oxford University Press.

Cova, B., Pace, S., \& Skålén, P. (2015). Brand Volunteering: Value Co-Creation with Unpaid Consumers. Marketing Theory, 15(4), 465-485.

Dolan, R., Conduit, J., Fahy, J., \& Goodman, S. (2015). Social Media Engagement Behaviour: A Uses and Gratifications Perspective. Journal of Strategic Marketing, 13(4), 1-17.

Duffett, M. (2013). Introduction: Directions in Music Fan Research: Undiscovered Territories and Hard Problems. Popular Music and Society, 36(3), 299-304.

Edvardsson, B., Tronvoll, B., \& Gruber, T. (2011). Expanding Understanding of Service Exchange and Value Co-Creation: A Social Construction Approach. Journal of the Academy of Marketing Science, 39(2), 327-339.

Fast, K., Karlsson, M., \& Örnebring, H. (2016). Metaphors of Free Labor: A Typology of Unpaid Work in the Media Sector. Media, Culture \& Society, 38(7), 963-978.

Fiske, J. (1992). The cultural economy of fandom. The Adoring Audience: Fan Culture and Popular Media, In Lewis, L. The adoring audience: Fan culture and popular media. Psychology Press. pp. 30-49.

Galuszka, P. (2015). New Economy of Fandom. Popular Music and Society, 38(1), 25-43.

Gamble, J. \& Gilmore A. (2013). A New Era of Consumer Marketing? European Journal of Marketing, 47(11/12), 1859-1888.

Gamble, J. R., McAdam, R., \& Brennan, M. (2019). How User-centric Innovation is Affecting Stakeholder Marketing Strategies: Exploratory Findings from the Music Industry. European Management Review, 16(4), 1175-1193.

Gilmore, J. H., \& Pine, B. J. (2007). Authenticity: What consumers really want. Boston: Harvard Business School Press.

Gioia, D. A., Corley, K. G., \& Hamilton, A. L. (2013). Seeking qualitative rigor in inductive research: Notes on the Gioia methodology. Organizational research methods, 16(1), 15-31.

Gray, J., Sandvoss, C., \& Harrington, C. L., eds. (2017). Fandom: Identities and Communities in a Mediated World. NYU Press.

Grönroos, C. \& Voima, P. (2013). Critical Service Logic: Making Sense of Value Creation and co- Creation. Journal of the Academy of Marketing Science, 41(2), pp.133-150.

Guschwan, M. (2012). Fandom, Brandom and the Limits of Participatory Culture. Journal of Consumer Culture, 12(1), 19-40.

Hao, A. (2020). Understanding Consumer Fandom: Literature Review and Conceptual Framework. In: C. Wang, ed., Handbook of Research on the Impact of Fandom in Society and Consumerism. IGI Global, pp. 18-37.

Hepworth-Sawyer, R., Hodgson, J., Paterson, J., \& Toulson, R. (Eds.). (2019). Innovation in Music: Performance, Production, Technology, and Business. Routledge.

Hills, M. (2003). Fan Cultures. Routledge.

Hine, C. (2015). Ethnography for the Internet: Embedded, Embodied and Everyday. London: Bloomsbury Academic. Hochschild, A. R. (2012). The Managed Heart: Commercialization of Human Feeling. University of California Press. 
Holt, D. B. (2004). How Brands Become Icons: The Principles of Cultural Branding. Harvard Business Press, Boston, MA.

Horton, D. \& Wohl, R. (1956). Mass Communication and Para-Social Interaction: Observations on Intimacy at a Distance. Psychiatry, 19(3), 215-229.

Ind, N., Iglesias, O., \& Schultz, M. (2013). Building Brands Together: Emergence and Outcomes of Cocreation. California Management Review, 55(3), 5-26.

Jaakkola, E. \& Alexander, M. (2014). The Role of Customer Engagement Behavior in Value Co-Creation: A Service System Perspective. Journal of Service Research, 17(3), 247-261.

Jenkins, H. (1992). Textual Poachers; Television Fans and Participatory Culture, New York: Routledge.

Jenkins, H. (2006). Fans, Bloggers and Gamers. Exploring Participatory Culture. New York: New York University Press.

Jenkins, H., Ford, S., and Green, J. (2013). Spreadable Media, Creating Value and Meaning in a Networked Culture. New York: New York University Press.

Livingstone, S. (2019). Audiences in an Age of Datafication: Critical Questions for Media Research. Television \& New Media, 20(2), 170-183.

Löbert, A. (2012). Fandom as a Religious Form: On the Reception of Pop Music by Cliff Richard Fans in Liverpool. Popular Music, 31(1), 125-141.

Maffesoli, M. (1995). The Time of the Tribes: The Decline of Individualism in Mass Society. Sage.

Malthouse, E. C., Haenlein, M., Skiera, B., Wege, E., \& Zhang, M. (2013). Managing Customer Relationships in the Social Media Era: Introducing the Social CRM House. Journal of Interactive Marketing, 27(4), 270-280.

Marcus, G. E. (1995). Ethnography in/of the World System: The Emergence of Multi-Sited Ethnography. Annual Review of Anthropology, 24, 95-117.

Marsh, J. (2014). From the wild frontier of Davy Crockett to the wintery fiords of Frozen: changes in media consumption, play and literacy from the 1950s to the 2010s. International Journal of Play, 3(3), 267-279.

McAlexander, J. H., Schouten, J. W., and Koenig, H. F. (2002). Building Brand Community. Journal of Marketing, 66(1), 38-54.

Morhart, F., Malär, L., Guèvremont, A., Girardin, F., \& Grohmann, B. (2015). Brand authenticity: An integrative framework and measurement scale. Journal of Consumer Psychology, 25(2), 200-218.

Muñiz, A. and O'Guinn, T. (2001). Brand Community. Journal of Consumer Research, 27(4), 412-32.

Muntinga, D. G., Moorman, M., \& Smit, E. G. (2011). Introducing COBRAs. International Journal of Advertising, 30(1), 13-46.

Music Ally (2019). News, Insights and Data. [online] Available at: https://musically.com/insight [Accessed 24 March 2020].

Obiegbu, C. J., Larsen, G., Ellis, N., \& O’Reilly, D. (2019). Co-Constructing Loyalty in an Era of Digital Music Fandom. European Journal of Marketing, 53(3), 463-482.

O'Reilly, D., Larsen, G., Kubacki, K., \& Larsen, G. (2013). Music, markets and consumption. Oxford: Goodfellow Publishers Limited.

O'Reilly, K. (2012). Ethnographic Methods: The Practice of Ethnography. 2nd ed. London: Routledge.

Pink, S. (2016). Digital Ethnography. Innovative Methods in Media and Communication Research, In Kubitschko, S., \& Kaun, A. (Eds.). Innovative methods in media and communication research. Cham: Springer International Publishing. pp. 161-165.

Pongsakornrungsilp, S. \& Schroeder, J. E. (2011). Understanding Value Co-Creation in a Co-Consuming Brand Community. Marketing Theory, 11(3), 303-324.

Postill, J. \& Pink, S. (2012). Social Media Ethnography: The Digital Researcher in a Messy Web. Media International Australia.

Sandvoss, C. (2005). Fans: The Mirror of Consumption. Polity.

Saragih, H. (2019). Co-Creation Experiences in the Music Business: A Systematic Literature Review. Journal of Management Development, 38(6), 464-483.

Schau, H., Muñiz, A., \& Arnould, E. (2009) How Brand Community Practices Create Value. Journal of Marketing, 73(5), 30-51.

Schroeder, R. (2014). Big Data and the Brave New World of Social Media Research. Big Data \& Society, 1(2), 1-11. 
Schrøder, K. C. (2019). Audience Reception Research in a Post-broadcasting Digital Age. Television \& New Media, 15(1).

Scolari, C. A. (2009). Transmedia Storytelling: Implicit Consumers, Narrative Worlds, and Branding in Contemporary Media Production. International Journal of Communication 3(3), 586-606

Sorensen, A. \& Drennan, J. (2017). Understanding Value-Creating Practices in Social Media-Based Brand Communities. The Service Industries Journal, 37(15-16), 986-1007.

Strauss, A. L. \& Corbin, J. M. (1990). Basics of Qualitative Research: Grounded Theory Procedures and Techniques. Sage Publications, Newbury Park, CA.

Terranova T. (2000). Free Labor. Social Text, 18(2), 33-58.

Vargo, S. \& Lusch, R. (2004). Evolving to a New Dominant Logic for Marketing. Journal of Marketing, 68(1), 1-17.

Vargo, S. L. \& Lusch, R. F. (2008). Service-Dominant Logic: Continuing The Evolution. Journal of the Academy of Marketing Science, 36(1), 1-10.

Vargo, S. L., \& Lusch, R. F. (2016). Institutions and Axioms: An Extension and Update of Service-Dominant Logic. Journal of the Academy of Marketing Science, 44(1), 5-23.

Van Dijck, J. (2009). Users like you? Theorizing Agency in User-Generated Content. Media, Culture \& Society, 31(1), 41-58.

Vesnic-Alujevic, Stehling, M., Jorge, A., \& Maropo, L. (2018). Algorithms and Intrusions: Emergent Stakeholder Discourses on the Co-option of Audiences, Creativity and Data. In: R. Das and B. Ytre-Arne, eds., The Future of Audiences. London: Palgrave Macmillan. pp. 101-119.

Yeritsian, G. (2018). Participation from above and below: Brand community and the contestation of cultural participation. Journal of Consumer Culture, 1469540518787576.

Zwick, D., Bonsu, S. K., \& Darmody, A. (2008). Putting Consumers to Work: Co-Creation and New Marketing Govern-Mentality. Journal of Consumer Culture, 8(2), 163-196. 